\title{
lliac vein compression: epidemiology, diagnosis and treatment
}

This article was published in the following Dove Press journal:

Vascular Health and Risk Management

\section{Qais Radaideh \\ Neel M Patel \\ Nicolas W Shammas \\ Midwest Cardiovascular Research Foundation, Davenport, IA, USA}

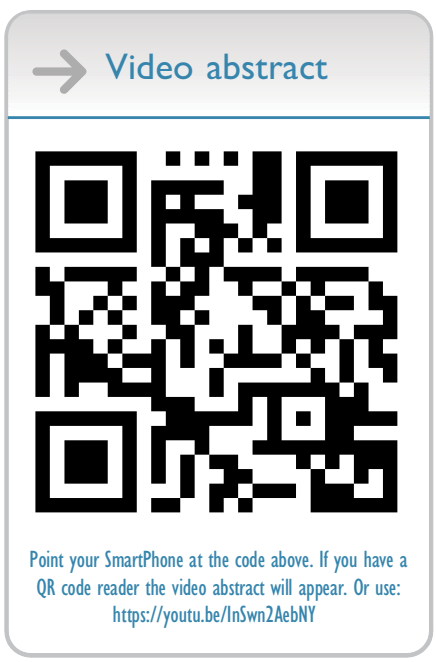

Correspondence: Nicolas W Shammas Midwest Cardiovascular Research Foundation, I622 E Lombard Street, Davenport, IA 52722, USA

Emailshammas@mchsi.com

\begin{abstract}
Iliac vein compression (LIVC) is a prevalent finding in the general population, but a smaller number of patients are symptomatic. ILVC should be considered in symptomatic patients with unexplained unilateral lower leg swelling. Patients typically complain of one or more of the following symptoms: lower leg pain, heaviness, venous claudication, swelling, hyperpigmentation and ulceration. ILVC can be thrombotic, combined with acute or chronic DVT, or non-thrombotic. ILVC is best diagnosed with intravascular ultrasound (IVUS), but computed tomography angiography (CTA) and magnetic resonance angiography (MRA) have emerged as valid screening tests. Venography underestimates the severity of ILVC but may provide insights into the anatomy and the presence of collaterals. Based on current available evidence, endovascular therapy with stenting remains the main treatment strategy for ILVC. Dedicated nitinol venous stents are currently under review by the Food and Drug Administration for potential approval in the United States. These stents have been released outside the US. There is no consensus to the optimal anticoagulation regimen post-ILVC stenting. Oral anticoagulants, however, remain a preferred therapy in patients with history of thrombotic ILVC.
\end{abstract}

Keywords: iliac vein, may-thurner, treatment, stent, imaging

Iliac vein compression (ILVC) or May-Thurner disease is a clinical syndrome of unilateral lower extremity swelling and pain due to venous hypertension caused by an iliac artery compressing an overlying iliac vein. Although the majority of ILVC are on the left, variants include right or bilateral iliac vein compression. ${ }^{1}$ The syndrome was initially described by May and Thurner in 1957 who noted that the chronic pulsation of the overlying right common iliac artery over the left common iliac vein leads to the formation of spurs within the wall of the vein and subsequent deep vein thrombosis (DVT). ${ }^{2}$ Later Cockett and Thomas in 1965 further defined the syndrome in their first series of 57 cases and reported that it is more common in females and mostly affect the left leg. ${ }^{1}$ In this manuscript, we review ILVC, its epidemiology, diagnosis and treatment. Literature search was performed in PubMed and Google and included the following terms: May-Thurner, venous stenting, iliac vein compression and antithrombotic therapies in venous stenting. Relevant reviews were included.

\section{Epidemiology, symptoms and quality of life of patients with ILVC}

The true prevalence of ILVC is not known since the majority of patients are asymptomatic. In a retrospective study of 50 subjects by Kibbe et al, the prevalence of ILVC in an asymptomatic population evaluated by computed tomography was 
$24 \%{ }^{3}$ The authors concluded that the presence of ILVC is a normal anatomical variant. However, ILVC can be symptomatic when severe. It is estimated to be present in $2-5 \%$ of the patients who have venous disease. ${ }^{1,4}$ Also, in the setting of DVT, ILVC can be present in $18-49 \%$ of the cases and is 3 to 8 times more common on left side. ${ }^{1}$

Symptomatic ILVC can present with a variety of symptoms most commonly lower extremity swelling, claudication, hyperpigmentation, varicose veins and/or venous ulceration. Patients may report tighter shoes in the affected leg at the end of the day with more fatigue and swelling. ${ }^{5}$ The quality of life (QOL) in patients with ILVC is reduced, particularly in those who develop DVT with postthrombotic syndrome (PTS). Khan et al reported that DVT effect on QOL is noticeable years after the event. ${ }^{6}$ Van Korlaar et al noted that the decrease in QOL is related to symptom severity and development of PTS. ${ }^{7}$ In addition, Lubberts et al performed a large meta-analysis to assess health-related QOL in patients with DVT with at least one year of reported symptoms. ${ }^{8}$ Following a DVT, the QOL was equivalent to population norm but was reduced in patients who develop PTS. Similarly, in a prospective evaluation of QOL in patients with DVT, Khan et al reported that the average quality of life adjusted year (QALY) at 4 months following a DVT was similar to the general population; however, the presence of PTS was associated with poorer QOL score. ${ }^{9}$ Finally, in a study by Catarinella et al intervention on ILVC with stenting improved QOL in patients with or without PTS at 24month follow-up. ${ }^{10}$

\section{Diagnostic imaging}

Iliac vein compression (ILVC) is frequently encountered on computed tomography angiography (CTA) of the abdomen (Figure 1). In some studies, asymptomatic ILVC is considered a normal variant rather than a pathologic finding. ${ }^{5,11,12}$ There is no indication to treat asymptomatic ILVC. Therefore, imaging tests evaluating for the presence of ILVC in the general population are not warranted. A thorough history and physical exam are important to identify the clinical presence of ILVC in symptomatic patients with lower extremity discomfort, edema and/or discoloration. Noninvasive tests would probably have their best yield in these symptomatic patients where the test findings complement the clinical suspicion. Currently, there are several noninvasive diagnostic tests to image the iliac veins and determine the presence and severity of ILVC. These include color Doppler ultrasound, CTA and

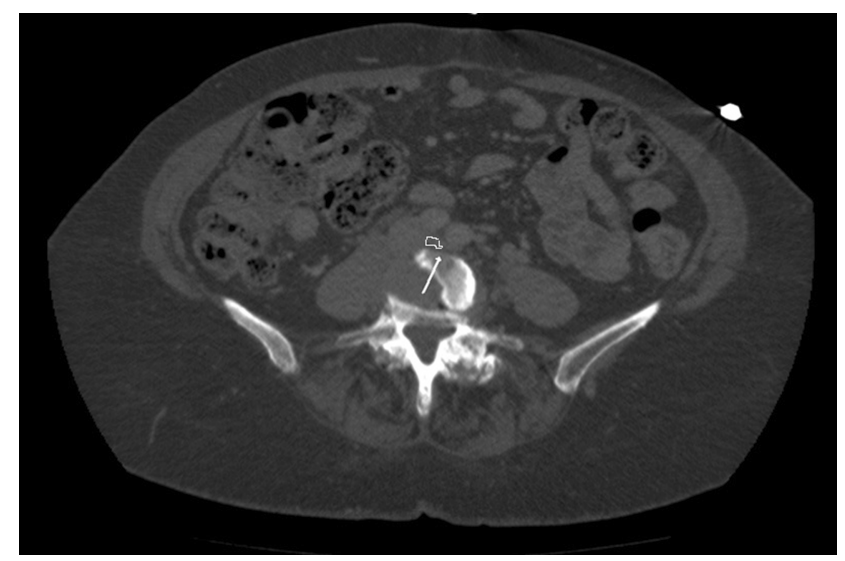

Figure I lliac vein compression visualized on computed tomography of the abdomen and pelvis (circled in white. White arrow pointing to the compressed left common iliac vein).

magnetic resonance imaging (MRI). The gold standard to evaluate ILVC is intravascular ultrasound (IVUS). Venography has underestimated the presence of ILVC. Below is a summary of these imaging modalities.

\section{Color Doppler ultrasound}

Color Doppler ultrasound (DUS) is typically the initial test employed in evaluating ILVC because it is noninvasive, readily accessible, easy to perform, safe and costeffective. ${ }^{5,13}$ Examination of the common femoral veins (CFV) and iliocaval veins is performed using a linear array probe at 4-7 megahertz $(\mathrm{MHz})$ and 2-3 $\mathrm{MHz}$, respectively. ${ }^{5,13}$ DUS is highly accurate in detecting venous insufficiency and acute iliofemoral deep vein thrombosis (DVT), findings that are associated with ILVC. ${ }^{5,11,12}$ However, DUS is of low sensitivity to assess the iliac veins in the pelvis because of their deep location. ${ }^{13}$ The overall sensitivity of ILVC visualization on ultrasound is reportedly $79 \%$ in the external iliac vein and $47 \%$ in the common iliac vein. ${ }^{13}$ Underlying bowel gas, obesity and variability in sonographer techniques prevent adequate visualization of iliac veins in $20-50 \%$ of the exams. ${ }^{12,13}$

Additionally, DUS does not distinguish specific anatomical characteristics of ILVC such as location of compression or the presence of intraluminal spurs. ${ }^{14,15}$ In one study, a flow volume in the right CIV $40 \%$ greater than a flow volume in the left CIV would be suggestive of ILVC. Labropolous et al described further ultrasound signs indicative of downstream compression: 1) color flow demonstrates mosaic flow, indicating post-stenotic turbulence due to proximal venous stenosis; 2) pulse 
Doppler shows absence of flow at area of stenosis; 3) absence of phasic blood flow; 4) abnormal Valsalva response with continuous flow during maneuver; 5) peak vein velocity ration of $>2.5$ across the stenotic region. ${ }^{11}$

Overall, DUS is a useful initial diagnostic test for determining venous insufficiency, but providers should have a low threshold to pursue further diagnostic testing as needed if the clinical suspicion for ILVC is high.

\section{Computer tomography angiography (CTA)}

CTA with venous filling (CTV) has been used to predict the presence of ILVC. CTV offers a comprehensive vascular evaluation including the arterial and venous systems. ${ }^{14}$ Images taken in the axial view are best for direct visualization of the IVC and the iliac veins. ${ }^{5,14}$ A CTV scan utilizing 10 -mm slices does not always offer proper diagnosis, as small iliac spurs and fibrosis are too difficult to visualize. ${ }^{12}$ Instead, 3- to 5-mm cuts are needed to identify areas of stenosis and factors causing iliac vein compression. 5,11,12

Several studies have found CTV to have an acceptable sensitivity and specificity in diagnosing ILVC. It can differentiate between thrombotic and non-thrombotic obstruction and is more accurate than ultrasound in identifying iliofemoral vein thrombosis. ${ }^{13}$ In addition, in a symptomatic patient, the presence of collaterals on CTV will also support the diagnosis of ILVC. $^{13}$ Furthermore, CTV can also help exclude alternate causes of compression such as pelvic mass and malignancies.

Limitations of CTV include radiation exposure and the risk of radiocontrast nephropathy from contrast dye. Dehydration can lead to overdiagnosis of ILVC. ${ }^{5}$ Also, accurate timing of administration of contrast to imaging sequences is critically important. Often, CTV may lead to non-diagnostic results. ${ }^{11}$

\section{Magnetic resonance imaging (MRI)}

Like CT venography, MRI has a high sensitivity and specificity in confirming diagnosis of ILVC. ${ }^{13,14}$ In addition, MR venography (MRV) allows for the ability to appreciate retrograde flow in the ipsilateral iliac vein and visualize collateral veins. ${ }^{14}$ Furthermore, it emits no ionizing radiation and provides detailed evaluation of obstructions with less chance of harm to the patient. ${ }^{12,13}$ However, MRV is contraindicated with older generation pacemakers and other metallic implants. Also, it may not account for non-laminar venous flow which may be seen in patients with ILVC. ${ }^{11,13}$

\section{Intravascular ultrasound}

The gold standard for ILVC is conventional venography with intravascular ultrasound (IVUS). ${ }^{5}$ IVUS provides high-resolution images utilizing a $12.5 \mathrm{MHz}$ catheterbased probe from within the vein. $5,11,14,15$ IVUS provides data on minimal luminal area at compression site, reference lumen area, signs of fibrosis and/or spurs within the vessel. IVUS does not utilize contrast or ionizing radiation. ${ }^{5,13}$ It is more sensitive than venography for detection of ILVC. ${ }^{16}$ In one study, single-plane venography noted $50 \%$ stenosis in 304 symptomatic limbs, whereas IVUS detected $80 \%$ compression in the same veins. ${ }^{11}$ Finally, the choice of the stent to treat the compression is best selected based on reference lumen area as seen by IVUS. ${ }^{15}$ The limitations of IVUS include invasiveness of the procedure, a lack of extravascular information, and a lack of prospective studies linking the use of IVUS to better outcome. ${ }^{11,13}$ Also earlier studies comparing IVUS to venography have used single-plane venography for comparison. This has likely increased the sensitivity of IVUS. ${ }^{5}$

\section{Venography}

Traditionally, contrast venography has served as the gold standard test for diagnosing ILVC, especially when treatment is indicated. ${ }^{13}$ There are several advantages to venography. First, it allows measuring pressure gradients across the area of compression which helps in understanding the functional significance of the lesion. A gradient $>2 \mathrm{mmHg}$ at rest and $>3$ $\mathrm{mmHg}$ during exercise convey hemodynamic significance. ${ }^{11,13}$ Second, it helps to determine the location and severity of the stenosis. Multiplanar views are important to increase the accuracy of venography including AP and lateral projections. Third, venography helps to define collaterals or the presence of congenital venous anomalies. ${ }^{17}$ Finally, blood flow patterns and the presence of thrombi can be detected by venography. ${ }^{13,15}$ However, venography is invasive and timeconsuming with an increased risk of bleeding. ${ }^{15}$ Additionally, it can only capture 2-dimensional images and does not contribute significantly to extravascular information. ${ }^{11}$ Finally, patients are exposed to radiation and contrast dye.

\section{Therapeutic options of ILVC}

In the last decade, endovascular management of ILVC has changed considerably. Given the fibrotic nature of the disease and significant recoil at the site of the compression, angioplasty alone is not an effective therapy with 
high rate of patency loss. ${ }^{18}$ Currently, there are no dedicated venous stents that have been approved for the treatment of ILVC in the US. These dedicated stents, however, were released outside the US over the past few years and are awaiting regulatory approval in the US. The Wallstent (Boston Scientific) has been the main stent used to treat ILVC on an off label basis in the US (Figure 2). The Wallstent has been shown to improve the patency and symptoms when compared to angioplasty alone. There are several drawbacks to this stent including a high rate of recoil and significant foreshortening when deployed making it difficult to position accurately at the compression site. ${ }^{19}$

Nitinol stents (Table 1) were recently developed to overcome several of the Wallstent problems. Nitinol stents do not foreshorten during deployment providing a more accurate positioning of the stent. ${ }^{39,40}$ Several of these stents have good outward and compression radial force
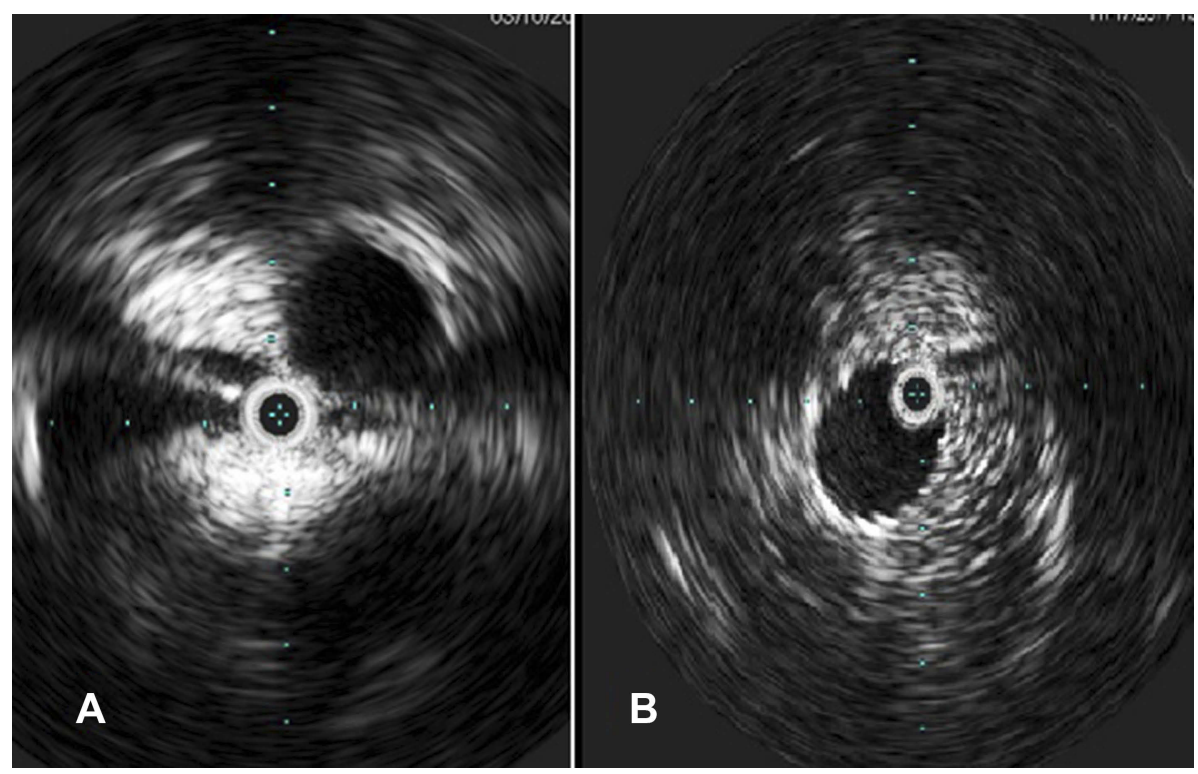

Figure 2 Intravascular ultrasound showing iliac vein compression (pretreatment, A) and post stenting (B).

Table I Stents used to treat iliac vein compression

\begin{tabular}{|c|c|c|c|c|c|c|}
\hline $\begin{array}{l}\text { Stent (manu- } \\
\text { facturer) }\end{array}$ & $\begin{array}{l}\text { VICI } \\
\text { (Boston } \\
\text { Scientific) }\end{array}$ & $\begin{array}{l}\text { Zilver Vena } \\
\text { (Cook) }\end{array}$ & $\begin{array}{l}\text { Sinus Venous } \\
\text { (Optimed) }\end{array}$ & $\begin{array}{l}\text { Venovo } \\
\text { (Bard) }\end{array}$ & $\begin{array}{l}\text { ABRE } \\
\text { (Medtronic) }\end{array}$ & $\begin{array}{l}\text { Wallstent } \\
\text { (Boston } \\
\text { Scientific) }\end{array}$ \\
\hline $\begin{array}{l}\text { Material/ structure/ } \\
\text { production }\end{array}$ & $\begin{array}{l}\text { Laser cut, open } \\
\text { cell, nitinol }\end{array}$ & $\begin{array}{l}\text { Laser cut, } \\
\text { open cell, } \\
\text { nitinol }\end{array}$ & $\begin{array}{l}\text { Laser cut, } 2 \text { open cell, } \\
\text { nitinol }\end{array}$ & $\begin{array}{l}\text { Laser cut, open } \\
\text { cell nitinol }\end{array}$ & Nitinol & Elgiloy \\
\hline Expansion & Self-expanding & Self-expanding & $\begin{array}{l}\text { Self-expanding, balloon } \\
\text { expandable at kissing } \\
\text { portion }\end{array}$ & Self-expanding & Self-expanding & Self-expanding \\
\hline $\begin{array}{l}\text { Sheath size/ } \\
\text { platform }\end{array}$ & 9F/0.035" & $6 \mathrm{~F} / 0.035^{\prime \prime}$ & $\mathrm{IOF}$ & $8,9,10 \mathrm{~F} / 0.035^{\prime \prime}$ & 9F/0.035" & 6-10F/0.035" \\
\hline Foreshortening & $\begin{array}{l}10-15 \% \text { fore- } \\
\text { shortening }\end{array}$ & $\begin{array}{l}\text { No foreshor- } \\
\text { tening }\end{array}$ & No foreshortening & $\begin{array}{l}\text { No } \\
\text { foreshortening }\end{array}$ & $?$ & $\begin{array}{l}30-40 \% \\
\text { foreshortening }\end{array}$ \\
\hline Radial force & ++++ & ++ & +++ & ++++ & $?$ & + \\
\hline Diameter & Up to $16 \mathrm{~mm}$ & Up to $16 \mathrm{~mm}$ & Up tol $8 \mathrm{~mm}$ & Up to $20 \mathrm{~mm}$ & Up to $20 \mathrm{~mm}$ & Up to $24 \mathrm{~mm}$ \\
\hline Length & $60-120 \mathrm{~mm}$ & $\begin{array}{l}60,100,140 \\
\mathrm{~mm}\end{array}$ & $60-150 \mathrm{~mm}$ & $40-160 \mathrm{~mm}$ & $40-150 \mathrm{~mm}$ & 20-94 mm \\
\hline Trial & VIRTUS & VIVO (EU) & Lichtenberg et al ${ }^{45,41}$ & VERNACULAR & ABRE & None \\
\hline
\end{tabular}

Note: ++++ , strongest; +++, strong; ++,weak; +, weakest; ?, unknown. ${ }^{46}$

Abbrivation: $\mathrm{F}$, French; $\mathrm{mm}$, Millimeter. 
and crush resistance and are flexible enough to take the shape of the iliac veins. There are no comparative data between the Wallstent and the new nitinol stents with respect to patency and target lesion revascularization.

In order to overcome some of the problems of the Wallstent, Raju and colleagues have used the $Z$ stent (Cook) as an extension of the Wallstent. The $\mathrm{Z}$ stent can extend the Wallstent if the compression is missed or when bifurcating stenting is needed into the IVC. Also, the $\mathrm{Z}$ stent can overcome the recoil of the Wallstent at the compression site. The $\mathrm{Z}$ stent provides more radial strength, and given its wide-spaced struts, it prevents jailing the contralateral iliac vein. It is typically deployed $1-2 \mathrm{~cm}$ extending into the IVC. In their study of 211 patients, Raju et al reported primary patency of $96 \%$ at 24 months. ${ }^{19}$ The $\mathrm{Z}$ stent, however, has its limitations. First, the stent is short. Second, contralateral thrombotic occlusions could happen on the $\mathrm{Z}$ stent when it is placed over a Wallstent that has been deployed higher than intended into the IVC. It is expected that the use of the $\mathrm{Z}$ stent will likely become less needed when the venous nitinol stents are approved in the US given their accuracy of deployment and less recoil.

Data on dedicated venous stents have recently been released. The Venovo stent (Bard) was recently evaluated in the VERNACULAR pivotal trial. ${ }^{20}$ In this prospective, multicenter, multinational single arm prospective study 156 patients completed follow-up at the time of the presentation of the data at VIVA 2018. All 219 stents were successfully deployed. The primary patency at 12 months was $88.3 \%$ which was significantly better than the performance goal (74\%) derived from the venous stent literature $(p<0.0001)$. Of these patients, 84 had PTS and 72 patients had nonthrombotic ILVC. Furthermore, data on the VICI stent (Boston Scientific) were released at LINC 2019 in Leipzig, Germany. In the VIRTUS trial, 170 patients were enrolled (127 post-thrombotic and 43 non-thrombotic). Of these, 7 patients withdrew. Primary patency of this cohort based on both venography and DUS when venography data was not available was $84 \%$. Primary patency based on venography only (available on 125 patients) was reported at $79.8 \%$ for post-thrombotic lesions and $96.2 \%$ for nonthrombotic lesions. There were $98.8 \%$ freedom from major adverse events. In a retrospective study by Neglen et al, data on 5-year patency post-ILVC stenting was presented in 982 lesions. The 72-month primary patency, assistedprimary patency and secondary cumulative patency rates were $79 \%, 100 \%$ and $100 \%$ in non-thrombotic disease and $57 \%, 80 \%$ and $86 \%$ in thrombotic disease, respectively. ${ }^{21}$
The durability of stenting ILVC appears to be good; however, constant surveillance may be necessary to identify stent restenosis or occlusion and intervene as needed.

\section{Stenting of ILVC in the setting of DVT}

Health care costs from veno-thromboembolic disease (VTE) are estimated to be around $\$ 10$ billion dollars annually, with most of the cost rising from treating the long-term consequences of $\mathrm{DVT}^{22}$ Previous studies have shown that $80 \%$ of the patients with iliofemoral DVT have an underlying venous stenosis proximally, which has to be treated to restore good venous outflow after thrombolysis. ${ }^{23}$

The presence of DVT in the iliofemoral region is highly predictive of PTS. ${ }^{24}$ PTS is characterized by a spectrum of skin changes, limb swelling and pain, which is a result of venous reflux and venous hypertension. Pardoni et al noted that the incidence of PTS is around 25-50\% after DVT involving the iliofemoral region. ${ }^{25}$

In the setting of acute DVT, catheter-directed thrombolysis (CDT) has been used to treat thrombotic occlusions. It involves introducing an infusion catheter into the venous system and administering a thrombolytic agent. T-PA is typically used at a rate of 0.5 to $1.0 \mathrm{mg} / \mathrm{hr}$. Typically, $10 \mathrm{mg}$ of tPA is placed in a $1 \mathrm{~L}$ bag of normal saline and infused at a rate of $50 \mathrm{cc}$ or $100 \mathrm{cc}$ per hour. Recently, the EKOS lysis catheter (BTG) has been used to treat DVT with good results in observational studies ${ }^{26}$ Pharmacomechanical therapy (PMT) has also been used to treat thrombotic occlusions. ${ }^{27}$ The Angiojet system (Boston Scientific) and other clot-retrieving devices have been used successfully in removing thrombus and restoring iliac vein patency.

Data on lysis in treating acute DVT have been conflicting. However, despite negative results from trials such as the CaVenT study and the ATTRACT trial, there is a general agreement that iliofemoral DVT should be aggressively treated to prevent PTS with CDT or PMT. $^{28-31}$ At this time, femoropopliteal DVT are best treated with anticoagulation only. A recent metanalysis comparing CDT with anticoagulation in treating iliofemoral DVT has shown an odds ratio of 0.38 (95\% CI, 0.26-0.55) for development of PTS with CDT compared to anticoagulation only. ${ }^{32}$ Also, the patency rate after CDT was much higher at 6-month (OR 4.76, 95\% CI, 2.14-10.56) $(p<0.0001)$. Furthermore, the quality of life after lytic treatment of iliofemoral DVT was significantly better than with oral anticoagulation only, particularly when done in the first 3 weeks after the event. ${ }^{33,34}$ 
DVT is associated with ILVC. Almost $80 \%$ of the patients with iliofemoral DVT have proximal venous stenosis which highlights the importance of treating the compression for short and long term continued patency. ${ }^{21,35}$ Stenting is the most effective way to treat these lesions as balloon angioplasty alone is inadequate. The lower end of the stent is likely to be extended into the common femoral vein and often placed just above the profunda femoral veins confluence. The stent is also extended into the IVC to ensure good coverage of the compression.

Patients with iliofemoral DVT should undergo routine IVUS to evaluate for ILVC. CTA is also an effective tool in identifying ILVC, whereas venography in general is suboptimal. ${ }^{16}$ One criticism of the ATTRACT trial is the lack of a requirement to perform IVUS on patients with iliofemoral DVT and therefore ILVC may have been missed in a good number of patients compromising patency and outcome. $^{30}$ In fact, the ATTRACT trial did not require follow-up DUS of the iliac vein post treatment and therefore the open vein hypothesis was not tested in this study. ${ }^{29}$

Although venous hypertension is diminished by eliminating the presence of ILVC, the increase in venous flow may worsen venous reflux in a relatively small number of patients $^{36}$. Combining stenting of the ILVC with venous reflux treatment may be optimal to improve patients' symptoms. $^{21,33,37}$

\section{Stenting of ILVC in chronic venous occlusions}

In symptomatic patients with chronic venous occlusions, the use of ultrasound accelerated lysis prior to stenting of ILVC has been shown to yield good patency. In the ACCESS PTS study, 78 patients (82 limbs) with mean DVT time of 13.2 months were evaluated after this treatment and $67 \%$ of them had a 4-point reduction in their Villalta score. $^{38}$ Similarly, the VCSS score improved at 1 year from a score of 12 to 6.9 $(p<0.0001)$. Finally, the quality of life measured by the VEINES-QOL score improved from a baseline score of 61.1 to 79.9 .

\section{Conclusion}

Diagnosis of ILVC is important to symptomatic patients as current treatment with stenting is effective in improving symptoms and QOL. CTA and MRA are acceptable screening tools, but the gold standard remains IVUS. Venography underestimates the presence of ILVC. The recent data from the VERNACULAR (venovo stent) and the VIRTUS (VICI stent) trials are reassuring with the new dedicated venous stents. These stents offer the advantage of accurate deployment and high resistive outward and compression radial force. Currently, there is no comparative data between venous stents. There is no consensus to the optimal antiplatelet or anticoagulant regimen following venous stent placement. There is also considerable debate to the effectiveness of antiplatelets when added to an oral anticoagulant post-venous stent. In post-thrombotic venous stenting, the general consensus is to keep oral anticoagulation for at least 6 to 12 months or indefinitely in patients with prior history of DVT or thrombophilia. For non-thrombotic iliac vein compression, antiplatelets or anticoagulants or both have been used by various operators with no comparative data to their effectiveness. ${ }^{42-45}$ Finally, there are no comparative data between direct oral anticoagulants (DOAC) and warfarin in post-venous stenting.

\section{Disclosure}

Dr Shammas receives educational and research grants from Bard, Boston Scientific and Intact Vascular. The authors report no other conflicts of interest in this work.

\section{References}

1. Cavalcante LP, Dos Santos Souza JE, Pereira RM, et al. Iliac vein compression syndrome: literature review. J Vasc Bras. 2015;14:78-83. doi:10.1590/1677-5449.20140027

2. May R, Thurner J. The cause of the predominantly sinistral occurrence of thrombosis of the pelvic veins. Angiology. 1957;8:419-427. doi: $10.1177 / 000331975700800505$

3. Kibbe MR, Ujiki M, Goodwin AL, Eskandari M, Yao J, Matsumura J. Iliac vein compression in an asymptomatic patient population. $J$ Vasc Surg. 2004;39:937-943. doi:10.1016/j.jvs.2003.12.032

4. Taheri SA, Williams J, Powell S, et al. Iliocaval compression syndrome. Am J Surg. 1987;154:169-172.

5. Knuttinen MG, Naidu S, Oklu R, et al. May-Thurner: diagnosis and endovascular management. Cardiovasc Diagn Ther. 2017;7(Suppl 3): S159-S164. doi:10.21037/cdt.2017.10.14

6. Kahn SR, Solymoss S, Lamping DL, Abenhaim L. Long-term outcomes after deep vein thrombosis: postphlebitic syndrome and quality of life. J Gen Intern Med. 2000;15:425-429. doi:10.1046/ j.1525-1497.2000.06419.x

7. Van Korlaar I, Vossen C, Rosendaal F, Cameron L, Bovill E, Kaptein A. Quality of life in venous disease. Thromb Haemost. 2003;90:27-35. doi:10.1055/s-0037-1613595

8. Lubberts B, Paulino Pereira NR, Kabrhel C, Kuter DJ, DiGiovanni CW. What is the effect of venous thromboembolism and related complications on patient reported health-related quality of life? A meta-analysis. Thromb Haemost. 2016;116:417-431. doi:10.1160/ TH16-02-0152

9. Kahn SR, Ducruet T, Lamping DL, et al. Prospective evaluation of health-related quality of life in patients with deep venous thrombosis. Arch Intern Med. 2005;165:1173-1178. doi:10.1001/archinte. 165.10.1173 
10. Catarinella FH, Nieman MA, de Wolf IM, et al. Quality-of-life in interventionally treated patients with post-thrombotic syndrome. Phlebology. 2015;30(Suppl. 1):89-94. doi:10.1177/02683555 15569431

11. Labropoulos N, Borge M, Pierce K, Pappas PJ. Criteria for defining significant central vein stenosis with duplex ultrasound. J Vasc Surg. 2007;46(1):101-107. doi:10.1016/j.jvs.2007.02.062

12. Brinegar KN, Sheth RA, Khademhosseini A, Bautista J, Oklu R. Iliac vein compression syndrome: clinical, imaging and pathologic findings. World J Radiol. 2015;7:375-381. doi:10.4329/wjr.v7.i11.375

13. Zucker EJ, Gnguli S, Ghoshhajra BB, Gupta R, Prabhakar AM. Imaging of venous compression syndromes. Therapy. 2016;6:519-532. doi:10.21037/cdt

14. White JM, Comerota AJ. Venous compression syndromes. Vasc Endovascular Surg. 2017;51:155-168. doi:10.1177/1538574417697208

15. Birn J, Vedantham S. May-thurner syndrome and other obstructive iliac vein lesions: meaning, myth, and mystery. Vasc Med. 2014;20:74-83. doi:10.1177/1358863X14560429

16. Shammas NW, Shammas GA, Jones-Miller S, et al. Predicting iliac vein compression with computed tomography angiography and venography: correlation with intravascular ultrasound. J Invasive Cardiol. 2018;30:452-455.

17. Shammas NW, Rachwan RJ, Daher G, Bou Dargham B. Double inferior vena cava and its implications during endovascular and surgical interventions: a word of caution. J Invasive Cardiol. 2017;29:51-53.

18. Park JY, Ahn JH, Jeon YS, Cho SG, Kim JY, Hong KC. Iliac vein stenting as a durable option for residual stenosis after catheterdirected thrombolysis and angioplasty of iliofemoral deep vein thrombosis secondary to may-thurner syndrome. Phlebology. 2014;29:461-470. doi:10.1177/0268355513491724

19. Raju S, Ward M Jr, Kirk O. A modification of iliac vein stent technique. Ann Vasc Surg. 2014;28:1485-1492. doi:10.1016/j. avsg.2014.02.026

20. Dake M. Available from: https://venousnews.com/vernacular-12month-data-successful-venovo-obstructive-lesions/. Accessed January 23, 2019.

21. Neglén P, Hollis KC, Olivier J, Raju S. Stenting of the venous outflow in chronic venous disease: long-term stent-related outcome, clinical, and hemodynamic result. J Vasc Surg. 2007;46:979-990. doi:10.1016/j.jvs.2007.06.046

22. Beckman MG, Hooper WC, Critchley SE, Ortel TL. Venous thromboembolism: a public health concern. Am J Prev Med. 2010;38: S495-501. doi:10.1016/j.amepre.2009.12.017

23. Kwak HS, Han YM, Lee YS, Jin G-Y, Chung G-H. Stents in common iliac vein obstruction with acute ipsilateral deep venous thrombosis: early and late results. J Vasc Interv Radiol. 2005;16:815-822. doi:10.1097/01.RVI.0000157690.91690.38

24. Kahn SR, Shrier I, Julian JA, et al. Determinants and time course of the post thrombotic syndrome after acute deep venous thrombosis. Ann Intern Med. 2008;149:698-707.

25. Prandoni P, Lensing AW, Cogo A, et al. The long-term clinical course of acute deep venous thrombosis. Ann Intern Med. 1996;125:1-7.

26. Shi Y, Shi W, Liang Chen L, et al. A systematic review of ultrasound-accelerated catheter-directed thrombolysis in the treatment of deep vein thrombosis. J Thromb Thrombolysis. 2018;45:440-451. doi:10.1007/s11239-017-1574-1

27. Rao AS, Konig G, Leers SA, et al. Pharmacomechanical thrombectomy for iliofemoral deep vein thrombosis: an alternative in patients with contraindications to thrombolysis. $J$ Vasc Surg. 2009;50:1092-1098. doi:10.1016/j.jvs.2009.06.050

28. Enden T, Haig Y, Klow NE, et al. Long-term outcome after additional catheter-directed thrombolysis versus standard treatment for acute iliofemoral deep vein thrombosis (the CaVenT study): A randomised controlled trial. Lancet. 2012;379(9810):31-38. doi:10.1016/S0140-6736(11)61753-4
29. Vedantham S, Goldhaber SZ, Kahn SR, et al. Rationale and design of the ATTRACT Study: a multicenter randomized trial to evaluate pharmacomechanical catheter-directed thrombolysis for the prevention of postthrombotic syndrome in patients with proximal deep vein thrombosis. Am Heart J. 2013;165:523-30 e3. doi:10.1016/j.ahj.2013.01.024

30. Vedantham S, Goldhaber SZ, Julian J, et al. Pharmacomechanical catheter-directed thrombolysis for Deep-Vein thrombosis. The ATTRACT Trial investigators. New Engl J Med. 2017;377:2240-2252. doi:10.1056/NEJMoa1615066

31. Wang W, Sun R, Chen Y, Liu C. Meta-analysis and systematic review of percutaneous mechanical thrombectomy for lower extremity deep vein thrombosis. J Vasc Surg Venous Lymphat Disord. 2018;6 (6):788-800. doi:10.1016/j.jvsv.2018.08.002

32. Li W, Chuanlin Z, Shaoyu M, Yeh CH, Liqun C, Zeju Z. Catheterdirected thrombolysis for patients with acute lower extremity deep vein thrombosis: a meta-analysis. Rev Lat Am Enfermagem. 2018;26: e2990. doi:10.1590/1518-8345.2309.2990

33. Oklu R, Wicky S. Catheter-directed thrombolysis of deep venous thrombosis. Semin Thromb Hemost. 2013;39:446-451. doi:10.1055/ s-0033-1334142

34. Comerota AJ, Throm RC, Mathias SD, Haughton S, Mewissen M. Catheter-directed thrombolysis for iliofemoral deep venous thrombosis improves health-related quality of life. $J$ Vasc Surg. 2000;32:130-137. doi:10.1067/mva.2000.105664

35. Hofmann LV, Kuo WT. Catheter-directed thrombolysis for acute DVT. Lancet. 2012;379:3-4. doi:10.1016/S0140-6736(11)61875-8

36. Delis KT, Bjarnason H, Wennberg PW, Rooke TW, Gloviczki P. Successful iliac vein and inferior vena cava stenting ameliorates venous claudication and improves venous outflow, calf muscle pump function, and clinical status in post-thrombotic syndrome. Ann Surg. 2007;245:130-139. doi:10.1097/01.sla.0000245 550.36159 .93

37. Neglen P, Thrasher TL, Raju S. Venous outflow obstruction: an underestimated contributor to chronic venous disease. J Vasc Surg. 2003;38:879-885. doi:10.1016/S0741-5214(03)01020-6

38. Venous news by Mark Garcia. Available from: https://venousnews. com/access-pts-study-brings-hope-for-post-thrombotic-syndromepatients/www.ClinicalTrials.govidentifier:NCT02159521. Accessd March 26, 2019

39. Available from: https://evtoday.com/device-guide/europe/chart.asp? id=155. Accessed January 23, 2019.

40. Available from: https://veindirectory.org/magazine/article/industryupdates/update-on-venous-stents. Accessed January 23, 2019.

41. Lichtenberg M, de Graaf R, Stahlhoff WF, Özkapi A, Simon M, Breuckmann F. Patency rates, safety and clinical results of the sinusObliquus venous stent in the treatment of chronic ilio-femoral venous outflow obstruction - data from the Arnsberg venous registry. Vasa. 2018;1-6. doi:10.1024/0301-1526/a000772.

42. Milinis K, Thapar A, Shalhoub J, Davies AH. Antithrombotic therapy following venous stenting: international delphi consensus. Eur J Vasc Endovasc Surg. 2018;55(4):537-544. doi:10.1016/j.ejvs.2018.01.007

43. Endo M, Jahangiri Y, Horikawa M, et al. Antiplatelet Therapy is Associated with Stent Patency After Iliocaval Venous Stenting. Cardiovasc Intervent Radiol. 2018;41(11):1691-1698. doi:10.1007/ s00270-018-2062-5

44. Padrnos LJ, Garcia D. May-Thurner syndrome and thrombosis: A systematic review of antithrombotic use after endovascular stent placement. Res Pract Thromb Haemost. 2018;3(1):70-78. eCollection 2019 Jan. doi:10.1002/rth2.12156.

45. Stuck AK, Reich T, Engelberger RP, Sebastian T, Kucher N. Endovascular treatment of post-thrombotic and non thrombotic iliofemoral venous outflow obstructions with self-expanding nitinol stents. Vasa. 2018;47(4):319-325. doi:10.1024/0301-1526/a000697

46. Dabir D, Feisst A, Thomas D, et al. Physical properties of venous stents: an experimental comparison. Cardiovasc Intervent Radiol. 2018;41:942-950. 


\section{Publish your work in this journal}

Vascular Health and Risk Management is an international, peerreviewed journal of therapeutics and risk management, focusing on concise rapid reporting of clinical studies on the processes involved in the maintenance of vascular health; the monitoring, prevention and treatment of vascular disease and its sequelae; and the involvement of metabolic disorders, particularly diabetes. This journal is indexed on PubMed Central and MedLine. The manuscript management system is completely online and includes a very quick and fair peerreview system, which is all easy to use. Visit http://www.dovepress. com/testimonials.php to read real quotes from published authors. 